Post-sampling procedure affects the measured nutritive value of perennial ryegrass

(Lolium perenne) T.M. Dale, R.M. Greenfield, K.N. Tozer and C.A. Cameron

Implementing change: barriers and opportunities T.A. Nelson, M.A. Brown, S.J. Fiekle, A.D. Mackay, P.R. Payne, A.P. Rhodes and W. Smith

ACKNOWLEDGEMENTS

NZGA PRESIDENT'S REPORT FOR 2015/2016 275

NZ GRASSLAND TRUST ANNUAL REPORT 2016-2017

AUTHOR INDEX

KEYWORD INDEX

INFORMATION FOR CONTRIBUTORS

COME AND JOIN US

\section{Levy oration - 2016 \\ Lessons learnt and future opportunities}

R.B. GREEN

184 Hayes Road, 4RD, Christchurch 7674, New Zealand richard.green@greenvale.co.nz

It is indeed a great honour and a privilege to be recognised by my peers with the prestigious Levy Oration award. There are so many people that have supported me throughout my career, many of whom are in this room today. I have always tried to just get on with things and do my bit for the industry, often through connecting people and ideas. Receiving an award like this is very humbling, particularly when considering how many people make a difference in their own way to our great pastoral industry.

Given that I am only half way through my career, I thought I would use about half my time to reflect on and share the things I have learnt to date, and then to look ahead and share my thoughts on what I think needs to happen to realise the potential of our Agri-food industry.

So what have I learnt over the first half of my career? I consider the key difference between New Zealand farming and agricultural research, and the rest of the world (other than a lack of subsidies), is our "systems" approach. Our agricultural universities have always had methods and approaches to teaching that produces generalists or integrators who can fit technologies into farm systems. Moving down the path of more specialisation, the "systems approach" to farming must be built on and enhanced.

It is absolutely clear that "science discovery" and farmer adoption and innovation is the engine that powers New Zealund a New Zealand and role of the New Zealand Grassland Association (NZGA) "Fuelled by Science and Tenpered by Experience" is just as appropriate today as it was when it was developed $10+$ years ago. To me this means connecting the farmers and industry with science with all the feedback loops that drive innovation. Innovation has always underpinned New Zealand farming and will continue to do so in the future.

I have learnt that "soft skills" or interpersonal skills and emotional intelligence are just as important as "hard skills" or technical knowledge. Soft skills were never even talked about when I started my career. I often think back to how much more I could have achieved as an agricultural consultant if I had understood that the way a message is delivered is more important than the message itself. I have been far more effective as a communicator since I have understood my own communication and behavioural style and been able to better understand others.

It has become obvious to me that the best investments hat I have ever made have been into my own personal development. I remember when I joined The Ministry of Agriculture and Fisheries (MAF) we were allocated \$5 000/ consultant/ year for training and using every dollar plus some. Annually, I still invest a considerable sum in personal development and believe there is at least a $\$ 10$ return on every $\$ 1$ invested in this area. I have also been fortunte to have travelled both in our seed business and tour honey business. I spent 100 night overseas/year for 10 years so got to understand som key markets. One of my key learnings over this time was that the consumer actually controls the value chain, not supermarkets or farmers, as we often think. We might not always agree with our targeted customer's views on our farming practices, but must appreciate that over time their perception needs to become a reality.

I have observed and learnt first-hand how critical it is for a business to have a clear purpose and vision and then a plan for success. I remember as a MAF consultant running field day or discussion groups about some new innovation or business practice that would lead to greater profits, and being extremely frustrated when no one would pick up the new idea soon discovered, however, that spinning the idea around so new innovations were demanded within a farm systems context was effective, rather than having to be pushed in isolation. I started focusing my che to be per a clear plan. I found that once business owners had a plan become highly motivated and driven to identify their current limitations and constraints, and change farming clear goals are absolutely critical in any business.

I have also learnt that the first 15 years of a career are the most import next 25 In farming and agribusiness these are the "grunt years" the time when the platform for a successful career is set. I am a strong advocate of making sure individual can be trained and mentored in their 20's, receiving as many experiences as possible, so they can be at the "top of their game" in their 30's. Succession is not planned well enough within agricultural businesses or within farming families. I have been involved as a chair of for success with defined goals and targets then they practices to improve performance. Clarity of vision an 
number of farming family meetings over the past 2 decades and think there is huge value in talking about the real hard topics that underpin succession, at least 10 years out from a succession event happening.

I have learnt that building a team of trusted advisors and mentors is invaluable, but then getting the best out of your advisors is a skill in itself. I have found the need to be very clear about my own business vision and identify other areas needing assistance to achieve the most from my advisors. It is also true that who you marry or have as your life-long partner is the most important decision you will ever make. To have a successful and sustainable business long-term requires both to recognise what success looks like, supporting each other when things get tough. I have been incredibly fortunate to have my wife, Vicki, as my best sounding board and confidant; she has given me a solid platform to build from.

After initially having "my head in the sand" I have now learnt to accept that both our consumers and the local community demand standards that farmers need to meet to retain the social licence to farm. Farmers now need to account for and justify the impact that farming practices have on the environment whether it is to the land, air or water. Farmers must accept the need to farm within the nutrient limits set as well as not just meeting, but exceeding, animal welfare standards.

Currently, this is probably one of the most turbulent or uncertain periods since the removal of farming subsidies in the 1980s. Our whole paradigms and thought patterns, let alone farming practices, are having to change. In the first 25 years of my career, successful farming business models revolved around intensifying production with increased stocking rates and per head performance, while retaining the same farm working expenditure as a percentage of the rising income. This strategy allowed us to keep up with the ongoing decline in the real terms of trade. The scary thing now is the these old business models will not work in future as in many catchments have reached or even exceeded maximum nutrient discharge levels. This is not just because of Regional Council rules, it is mainly driven by what our high-end customers and communities are saying. Farmers look to the market to say how to extract more value from our products, but this is not easy. New Zealanders have invested heavily in training and research and development (R\&D) for the past 100 years, and are global experts in growing forage and efficiently turning it into products. This nation has been fortunate to have had some preferred free-market access deal and strong demand for products, but have not invested enough in market development over recent decades. As a consequence, there are few people with deep market and customer understanding and the ability to develop brands, stories and connections with consumers. We are having to play catch-up very quickly.
I have learnt in our own businesses, the large returns that can be created through the development of Intellectual Property. Most farming business understand about the returns possible from investing in tangible assets such as land, stock, machinery and buildings, but have a poor understanding about the potential return and value from investing in intangible assets. These intangible assets could include brands and stories, patents or trademarks, as well as unique and stem and skills deve systo Agrifood sector to develop "inique points of difference" from our competitors, there is an urgent need to invest and develop intangible assets.

One thing that I have observed time and time again is that profitable businesses always have a simple and repeatable core business at heart. These businesses often look boring but consistently produce high levels of performance with a real focus on cash-flow. The managent team wihin these business lnow and mancent understand the bus we levers that drive profitability. The businesses are well systematised and have key non-negotiable targets or decision points in place. A problem for many business owners is that they often do not like the discipline around monitoring and reporting that goes with success, so these models are often not replicated throughout New Zealand. Historically, business discipline has not been a part of our national psyche. This needs to change, and is starting to with the All Blacks being an example. The All Blacks won the first world cup in 1987 because of good skills; they won the last two because of disciplined systems and being process driven.

I have learnt over the first half of my career that magic does happen and opportunities do come along regularly over the business life-cycle. What defines an individual or a business's success long-term is whether or not they capitalise on these opportunities. Only a few unique individuals are constantly scanning the horizon looking for opportunities so they recognise them when they come along. These successful individuals move quickly when they see an opportunity and "grab them with both hands" before many others have even woken up. Probably the key learnings for me from watching others do this well is to know what business success looks like, and to be surrounded by positive people and competent advisors who expand your thinking and confidence to act.

I have also learnt over the past 20 years to give time to things I am passionate about. We are extremely fortunate in New Zealand to have passionate volunteers keeping rural communities strong, as well as keeping national organisations running that are critical to our collective futures (such as NZGA). My personal experience is that the value received back from tithing time to an organisation is much more than any short- term cost it might have. It is quite true to say the more you give the more you receive in return.

What is my vision for the Agri-food sector over the next 20 years?

There is a need to aggressively re-engineer value chains to meet the needs of customers wanting premium products. Current value chains are mainly designed around commodity products. While I expect commodities will continue to be produced they need to form a smaller percentage than they do today. The new premium value chains will be supported by:

a. Traceability. With food safety being so critical in the high end markets, traceability and assurance schemes must be a given

b. Deep customer insights and a connection with these customers that makes our products stand out from other suppliers

c. Smart use of social media channels to get as many touch points with the targeted customers as possible - open access to what we do and how we do it?

d. Supply of product 52 weeks of the year or true rarity value through seasonality

e. Measurement and reporting against compliance standards for air, water and land externalities, but also against global best practice - be a leader as to what that means and looks like?

f. Co-branding and developing food baskets through partnerships with other New Zealand suppliers. Given our small scale and ability to feed only 50 million people, collaboration is needed.

The New Zealand Agri-food Industry needs to develop a "Pasture Fed" brand and standard across all our products. This will help differentiate New Zealand food products from competitors. Pasture needs to be seen as the new super-food. To underpin this Pasture Fed brand we need to develop our own unique agriculture story around our methods of production, our heritage and farming culture.

Innovation and adoption is more critical to success in the future than it has been in the past. This won't just be a linear adoption of technology, but where farmers can get synergistic benefits from technology adoption the sum of benefits will be greater than the individual parts. This could be where a new plant species is fed to an animal with a unique trait, supported by some precision farming technology. R\&D providers will need to continue doing their component research but will need to find ways to bring these various technologies together, potentially through modelling, but also in real life through demonstration farms utilising all the technology available to farmers within a real farming environment. Again, this reinforces the importance of farm systems and getting past funding deficits to think about new models to increase innovation. I think in the short to medium term serious international money will come into research programmes. Global companies are starting to recognise that within New Zealand there are close links between science, education, industry and business as well as the government as the regulator, all with a thirst for change and progress. These are all the components required for focused innovation and adoption. New Zealand has the opportunity to become ( yielding crop research. The research problems and opportunities, but with global spin-offs.

New farm ownership structures will continue to evolve with bank finance being replaced with more equity to make business more resilient, and allow a greater investment in non-bankable intangible assets. This will create more formal governance structures driven partially from the complexity of businesses, but also from future shareholders being passive investors in the business, quite renoved fom day to day magen for good governance in business, I am more concerned about the risks around not having the number and calibre of highly skilled managers to run large and complex businesses in the future. Ways to fast-track the development of these business managers are needed. This will require the development of a range of high-powered short executive courses providing professional and persona development training. To be successful employers must increase investment in staff training. Also, picking up on the point I made earlier and taking a leaf from the corporate world, talented young people in their 20 's must be identified and their development nurtured to give them the breadth of experience needed to be future leaders.

A separate huge challenge that is bigger than one individual to solve, is how to urgently train staff with the skills and expertise to connect branded products under a New Zealand Agri story with high-end consumers? These people will almost certainly be living "in-market" and be constantly getting real insights into what our customers want and identifying ways to shorten the value chain to get closer to them to add and collect more value. This is nothing new. Many innovative companies have been doing this for years with Zespri having just under half their 400 staff living in-market, but I want to see it happen on scale. We cannot, however, underestimate the investment and time that will be required to train these people and, unfortunately, even if we started this today we are about 10 years too late.

One of the exciting short-term opportunities will be around data measurement and reporting which will potentially add increased value to all businesses over the next few years. We have not yet been able to comprehend the opportunities for improvement from being able to focus on optimising output per square metre or animal compared to per paddock or mob. Data 
will provide managers with the information to reduce the variability in performance across animals and land, and reduce their impact on the environment. With these data available in the future, there is a huge need for systen integrators who can pull it together, interpret and turn it into practical recommendations. Farmers will require all IT providers to collaborate and work together so the information can be provided on a common IT platform, removing current problems and constraints in this area.

I am imagining a world where both farmers and other pather value chain partners will have realised the value of R\&D investment, and New Zealand will be investing $2-3 x$ more in $R \& D$, with new innovations rolling out to support agriculture. Investment in collective marketing and brand development will have not just doubled over the next 20 years, but will have grown by a factor of a least 4-fold from today's levels. While there will be cost in getting this going the long-term return will be large and this will be the only way fames will eve break out and wait for Govengent to dive this. Famers and industry bodies need to stand up and develop a clear and compelling vision for government to invest in.

Tourism is a sector that agriculture must work fa closer with as both industries need to leverage off each other to realise their potential, and make the New Zealand experience truly enduring. I recently had an international chef (whom I met on the top of a mountain) tell me that during her 3 week stay in New Zealand, she had experienced the freshest and tastiest food ingredients that she ever had in all her travels around the world. How do we allow global customers bitten by their Kiwi experience to continue directly buying premium food ingredients, daily, when they return home? I would love to see the "My Food Basket" concept expanded globally to a "Kiwi Food Basket". An on-going connection with our country via our food will encourage visitors to return and recommend the experience to their friends.

Over the next 25 years New Zealand farming businesses will need to develop greater resilience at al levels to live and thrive in a world experiencing globa warming. Climate change will shape all our thinking over the next few decades. Most farmers in the world are well prepared for climate change, but in New Zealand we seem slow to recognise and accept what is impacting on us already. Other things coming towards us at full speed that we need to be proactive about and not just react to when the issue blows up include:

a. Carbon emissions with agriculture potentially being included in an Emissions Trading Scheme

b. Tighter animal welfare standards with some current practices not being acceptable

Unintended results from micro-testing of our food products.
I am sure over the next 20 years the agricultural industry would have moved away from entrenched positions it holds today, and will have accepted that change is necessary and must be embraced. I hope that our industry and marketing organisations will be working far more seamlessly together and that an umbrella grouping has set a farmer-driven but consumer-lead vision for our Agri-food Industry. This same group may well be the spokesperson for the media on general agricult jecting a consistent and bat help make farmers and others in the industry feel less like victims, and hopefully, move farmer mind-sets more to accepting challenges and being proactive in trying to find solutions.

We all intuitively know that our future as a pastoral industry will be defined over the next $10-20$ years. My vision is that the pastoral industry will be recognised as being a cuse pas focused, and highly profised with an er-decreasing environmental footprint and an ever-increasing investment into branding, research, innovation and staff training, attracting the best and brightest into our sector and rewarding them well.

I honestly believe this vision can be realised, but alignment and unity right across the value chain from the farmer to the market will be needed. Firstly, agree on a common vision and purpose, and then commitment and capital from all players will follow. Structure follows strategy and agreement on a combined strategy or vision before jumping into discussing operating structures. Nothing will ever happen without first collaborating across our pastoral industry. This can be scary because it potentially involves change and often means giving up something.

But the prize in front of us is huge. Our industry can be recognised as being the restaurant for the 50 million high net worth foodies of the world. not grab this opportunity, then other countries will claim the moral high ground and the market positioning it enables. In my mind, retaining the status quo is not an option and is a far riskier than embracing the vision I am proposing. This is the industry I am wanting to be part of over the next 20 years of my career. Those just starting their careers are fortunate to have joined this fantastic industry at a critical time when some key strategic decisions need to be made. I encourage you to step up and ask lots ene the status quo, providing leadership not just observers in this industry, as it is your future that is at stake more so than for the existing players.

Finally, I would like to sincerely thank the NZGA Executive Committee for presenting me with this award. I would also like to acknowledge and honour those award winners who have gone before me, including last year's winner, the late Colin Holmes.

NZGA PRESIDENT'S ADDRESS 2016

Systems research: the need for a change of thinking

D.R. STEVENS

AgResearch, Invermay Research Centre, Private Bag 50034, Mosgiel, New Zealand david.stevens@agresearch.co.nz

Farm systems research has a long history of success in New Zealand. Recent reviews have highlighted the progress made through the traditional and pragmatic approaches that have been used (Clark 2013; Stevens et al. 2016). However, as the world and technologies change ever more rapidly around us, is it time to change from the pragmatic problem solving approach to one of deeper understanding?

Professor Shaun Hendy defined the need for new thinking at the launch of the recently formed Te Pungh thinking at the la Matatini, the Centre ofResearch Excellence for Complex Systems and Networks. He said "by understanding the networks that underlie each of these complex systems we will get insights into how to influence them and how to develop better strategies for managing them". The power of systems research provides the opportunity for New Zealand to define its own path and make its own decisions. These opportunities come through understanding how systems will respond, or how they can be reconfigured, to capture benefits specifically to meet our needs, rather than the needs of others.

A science critic and past research director suggested in a recent article that a focus on farm systems research (or application) was in the realm of primary industry farm advisory professionals, not the science effort (Allison 2016). He based his view on the notion that farmers will take up and incorporate technologies into their farming systems if and when the technology offers an improvement in value to the farmer. This belies the common belief that farm systems research is about demonstrating the value of technologies at a farmlet scale. Unfortunately this belief is flawed.

The argument presented is that farm systems research is about demonstrating the fit of technology into current systems. While this may be one option or outcome, the more fundamental reason for farming systems research is to understand what drives the system and alters the value of the system, and then begin to develop new systems that may return greater value. The concept of putting technologies into a current system has a tendency to rely on incremental gain. While this has some merit, it locks us into the current paradigm, rather than imagining new futures.

The key to understanding systems research is to understand the holistic nature of the approach. Traditional research is reductionist in approach (catabolic), breaking the system into its constituent parts and examining these in isolation, in the attempt to understand the base function of each component. This requires tight control to reduce internal variables and external influences. Systems research embraces this variation and examines the system in reference to the variables around the system that drive its performance. It is about synthesis (metabolism) of processes into functioning systems.

Systems science uses a holistic approach to study the system as a whole to understand the outcomes and properties of the system rather than the component parts. To demonstrate the nature of the difference between reductionist and holistic approaches we can use the bicycle as an analogy.

Do you own a bicycle? Most of the population of the world has ridden a bicycle. Is yours an old faithful for riding quietly to work or a state of the art road bike or mountain bike? Do you ride it for pleasure, necessity, exercise, competition or thrills? How much did your bicycle cost, and how much technology is embodied in your bicycle?

When disassembled into its component parts a reductionist approach would examine the gears, chains, levers, wheels etc. Each component may be high or low ech, made of steel or carbon fibre, precision made or roughly hewn.

When assembled the bicycle can do something that any one of the parts cannot. It exhibits emergent properties - it evolves into a mode of transport. That outcome cannot be readily seen from examining the components in isolation. Even when assembled, it is not finished. It needs a rider to complete a function have meaning or purpose. Then we have an operating system.

The system has a boundary that sits around the bicycle and the rider. The system sits within other systems, the road network or the track, for example, and so exhibits nesting. The system interacts with its surroundings; the friction of the road, the drag of the wind, and the motorists around it. And so it interprets its environmen and learns from feedback. The gears need to change, the effort of the rider has to increase, the brakes need to be applied, the car dodged. The system evolves. The penny farthing was replaced by the chain-driven cycle, the 10 -speed with the 18 -speed, and the mountain bike 